\title{
La paradójica centralidad de las teorías de la comunicación: debates y prospectivas $^{1}$
}

\section{Luis Ignacio Sierra Gutiérrez²}

\author{
No hay nada más práctico \\ que una buena teoría. \\ Kurt Lewin
}

\begin{abstract}
La vida no se mide por el número de veces que tomamos aliento, sino por los extraordinarios momentos que nos lo quitan.

Georges Carlin
\end{abstract}

Recibido: 2015-05-06

Enviado a pares: 2015-05-06

DOI: 10.5294/pacla.2016.19.1.2
Aprobado por pares: 2015-08-09

Aceptado: 2015-09-02

\section{Para citar este artículo / To reference this article / Para citar este artigo}

Sierra Gutiérrez, L. I. (Marzo de 2016). La paradójica centralidad de las teorías de la comunicación: debates y prospectivas. Palabra Clave, 19(1), 15-56. DOI: 10.5294/pacla.2016.19.1.2

\section{Resumen}

Dos asuntos relevantes han ocupado históricamente buena parte de los debates en el campo de la comunicación: los relativos a su constitución como campo de conocimiento específico y los atinentes a su producción teórica, más comúnmente conocidas como teorías de la comunicación. Este artículo se ocupa de recoger los principales debates en torno a estos dos asuntos

\footnotetext{
1 Este texto es el aporte personal del autor a la investigación: "Dinámicas y tendencias de la enseñanza universitaria sobre teorías de la comunicación-estudio comparativo en los programas de pregrado de formación profesional en Comunicación Social en Bogotá, D.C., Colombia”, realizada por los profesores investigadores del Departamento de Comunicación, de la Facultad de Comunicación y Lenguaje, de la Pontificia Universidad Javeriana: Luis Ignacio Sierra, José Miguel Pereira, Claudia Pilar García, Mónica Isabel Salazar, Carlos Barreneche, Roberto Sepúlveda, María Isabel Cortés, Roberto Sepúlveda, Áela Marcela Castellanos. Monitoras de investigación: Jimena Sterling, María Camila Alvarado. Investigación realizada entre agosto de 2013 y mayo de 2015.

2 Pontificia Universidad Javeriana, Colombia. lisierra@javeriana.edu.co
} 
y a la vez plantear cómo la discusión alrededor de la especificidad de dichas teorías ocupa una centralidad paradójica. Por una parte, no se rescinde de ellas, pero, por otra, su relevancia ocupa un segundo plano por privilegiar una formación más profesionalizante en campos aplicados de la comunicación. Se concluye ofreciendo algunas prospectivas de nuevos enfoques sobre estos asuntos vigentes en la comunicación.

\section{Palabras clave}

Campo de comunicación, teorías de la comunicación, epistemología de la comunicación, docencia en comunicación, teorías de rango medio (Fuente: Tesauro de la Unesco). 


\section{The Paradoxical Centrality of Communication Theories: Debates and Prospective}

\section{Abstract}

Two important issues have historically occupied much of the discussion in the field of communication: those relating to its constitution as a specific field of knowledge and theoretically pertaining to production, more commonly known as theories of communication. This article deals with collecting the major debates on these two issues as well as considers how the discussions about the specific nature of these theories occupy a paradoxical centrality. On the one hand, it has not terminated them, but on the other, its relevance is sidelined by favoring board skills in applied communication fields. We conclude by offering some prospects for new approaches to these existing issues in communication.

\section{Keywords}

Communication field, communication theory, communication epistemology, teaching communication, theories of the middle range (Source: Unesco Thesaurus). 


\section{A paradoxal centralidade das teorias das comunicações: debates e prospectivas}

\section{Resumo}

Dois assuntos relevantes têm ocupado historicamente boa parte dos debates no campo da comunicação: os relativos à sua constituição como campo de conhecimento específico e os atinentes à sua produção teórica, conhecido como teorias da comunicação. Este artigo trata de reunir os principais debates sobre esses dois assuntos e, ao mesmo tempo, propor como a discussão ao redor da especificidade dessas teorias ocupa uma centralidade paradoxal. Por um lado, elas não são invalidadas, mas, por outro, sua relevância ocupa um segundo plano por privilegiar uma formação mais profissionalizante em campos aplicados da comunicação. Conclui-se oferecendo algumas prospectivas de novos enfoques sobre esses assuntos vigentes na comunicação.

\section{Palavras-chave}

Campo de comunicação, teorias da comunicação, epistemologia da comunicação, docência em comunicação, teorias de médio alcance (Fonte: Tesauro da Unesco). 


\section{Introducción}

En el panorama general de la formación y docencia en Comunicación Social, la asignatura de Teorías de la Comunicación, aunque ha gozado de cierta favorabilidad y reconocimiento en el medio académico, tiende a reducirse cada vez más en los distintos planes de estudio; esto lo podemos observar y constatar al menos en nuestro contexto local y regional. La mayoría de los currículos la incluyen como componente básico aplicado en la formación de quienes se preparan para un ejercicio profesional específico como comunicadores, aunque con denominaciones diversas, y algunos pocos la incluyen como componente teórico previo a la formación aplicada.

No obstante, cuando se trata de precisar su naturaleza, objeto, contenidos e implicaciones, la tendencia es no solo a abordarlas de manera aplicada e instrumental a los distintos intereses profesionales, sino que empiezan a darse también los tropiezos sobre su pertinencia. Docentes, investigadores y estudiantes las perciben como un cúmulo de ambigüedades, dificultades y contradicciones para una adecuada caracterización y delimitación; asimismo, expresan incesantes cuestionamientos sobre su utilidad práctica. La verdad es que, en el contexto académico e investigativo, el tema como tal está abierto y es propicio para la investigación y el debate.

Dado que no pierde su vigencia, pensamos que, en el contexto de un proyecto sobre teorías de la comunicación, resulta más que lógico y necesario recuperar, así sea de manera parcial, lo que se ha investigado. Es preciso, así, clarificar lo que se entiende por teorías de comunicación y analizar el papel que desempeñan en el campo y el ejercicio de su docencia.

Un rápido sondeo revela que no solo ahora, sino desde hace ya varias décadas no pocos investigadores lo han hecho y se han ocupado de esta cuestión desde diferentes perspectivas. Cabe recordar que ya hacia finales de la década de 1950 Berelson (2004), al referirse a la inminente "muerte" del campo, sostenía la necesidad de explorar nuevas líneas para la investigación en comunicación. La preocupación central era de índole epistemológica, para evitar las repeticiones de las aproximaciones realizadas en la primera parte del siglo XX. 
De modo particular, en esta última década, investigadores del grupo español Mediación Dialéctica de la Comunicación Social de la Universidad Complutense de Madrid, bajo el liderazgo de José Luis Piñuel, se han ocupado de manera juiciosa de esta problemática, principalmente en sus implicaciones para la docencia universitaria, y han sostenido que

\begin{abstract}
[...] la teoría de la comunicación dentro del marco socio histórico de la llamada Sociedad del Conocimiento, se muestra como una necesaria fuente de conocimiento psicosocial, no solo como proveedora de objetos de estudio comunicacionales, sino como generadora de epistemes que permitan desarrollos teóricos y metodológicos para la investigación y para las prácticas sociales (Gaitán, 2010, citado en Águila y Cortés, 2011, p. 2).
\end{abstract}

En la perspectiva de Piñuel (2010), lograr proponer una "teoría de la comunicación” depende en buena parte de lograr clarificar su objeto de estudio y proponer un adecuado diseño epistemológico y metodológico que apunte a formular y solucionar problemas relevantes con ese objeto de estudio y sus aplicaciones prácticas.

El tema de por sí genera controversia tanto en lo teórico como en lo práctico, y no son pocos los interrogantes que sigue suscitando: ¿existen teorías de la comunicación? ¿Qué abarcan y qué plantean tales teorías? ¿Afectan de algún modo las teorías los procesos comunicativos de la vida real? ¿Tiene algún sentido hablar de teorías en un campo que está en permanente construcción? ¿Tienen alguna utilidad las teorías para la formación de los futuros profesionales dedicados al ejercicio instrumental de la información y la comunicación? Si sirven para algo, ¿para qué sirven? ¿Cuándo resulta más provechoso abordarlas, al final o al comienzo de la formación? ¿Qué se debería privilegiar en la formación teórica de los comunicadores? ¿Por qué insistir en encuadrarlas como requisito dentro del currículo académico? Si la comunicación, cada vez más es vista como espacio profesional de un saber práctico y aplicado, con un aparato conceptual limitado, ¿a qué viene tenerlas en cuenta en la formación teórica del comunicador? (Rizo, 2010).

Es decir, las distintas inquietudes plantean el reto de saber si al hablar de teorías de la comunicación estamos o no frente a un consolidado 
conceptual que pueda constituirse como paradigma disciplinario, y que sea susceptible, como sostiene Piñuel (2010), de integrar y reorganizar todos los saberes sobre la comunicación, o si al contrario estamos frente a aproximaciones categoriales variables de otras disciplinas sobre el fenómeno de la comunicación.

De lo que no cabe duda, y es nuestro presupuesto incondicional, es que el fenómeno de la comunicación, aparte de ser intrínseco al ser social, se ha convertido con el correr del tiempo en nervio estratégico central que dinamiza, irradia y transforma nuestras sociedades, nuestras culturas, nuestro medios, nuestras relaciones, afectándonos intrínseca y estructuralmente a todos (Rizo, 2012).

A modo de contextualización y provocación básica para nuestro propósito, cabe recoger aquí el reto que nos plantea Fuentes Navarro (2010):

La enseñanza de las teorías de la comunicación es una tarea académica especialmente desafiante por varias razones genéricas: pero fundamentalmente por una condición esencial: es una práctica que no puede realizarse sin auto-referirse, sin establecerse en dos niveles simultáneamente: nada puede enseñarse sobre la comunicación sin recurrir para ello a la comunicación. Las "teorías de la comunicación" deben ser comunicadas para ser tales, y el proceso de comunicarlas entre sujetos sociales concretos en entornos concretos, afecta de alguna manera su naturaleza meta comunicativa. También viceversa: Los modelos "teóricos" de la comunicación afectan de alguna manera la práctica comunicativa. Evidentemente, esta condición que puede resumirse en la premisa de la "doble hermenéutica" inherente a toda ciencia social, no se limita a la relación teoría/práctica de la comunicación en las aulas universitarias; pero es en esta situación particularísima donde su aprendizaje es eventualmente más relevante y difícil (pp. 7-8).

Nuestro interés aquí no es otro que el de asociarnos a las inquietudes planteadas por este investigador mexicano quien ha liderado por décadas la reflexión sobre estas cuestiones, es decir,

[...] ¿cómo generar una formación profesional clara y coherente, acorde con las particularidades de nuestro campo, que articule las diferentes vertientes de la comunicación, y que en el mejor de los 
casos, responda a las demandas formativas del actual escenario comunicativo? (Rizo, 2012, p. 13).

Dichas inquietudes han sido planteadas y enriquecidas por colegas mexicanos de amplia trayectoria, entre los que se cuentan Claudia Benassini, Margarita Reyna, Silvia Gutiérrez, Marta Rizo y Carlos Vidales, sin desconocer, por supuesto, el valioso aporte dado por otros investigadores latinoamericanos desde distintas latitudes.

En tal sentido, en la misma línea reflexiva e interpretativa sigue vigente el aporte de José Luiz Braga (2007), investigador brasileño, cuando afirma:

El principal problema, tal vez más que una definición de objeto 0 de fronteras, sería el de construir sentido en la diversidad de los núcleos de percepción y cuestionamiento, dentro del propio campo [...] Así, "constituir el campo de la comunicación" no debe ser pensado como elaborar un bloque monolítico de teorías que, de modo consensual, proporcionen explicaciones y preguntas. Como en todas las demás disciplinas humanas y sociales, escuelas, ángulos, tendencias de "explicación y preguntas" se confrontan —y es en la tensión mutua entre esas diferentes tendencias como se desarrollan buenas problematizaciones y se construye la propia disciplina (citado en Ferreira, 2007 , p. 8 y 15).

También es pertinente, pero en otro sentido, la interpelación Martino (2001) sobre si en realidad existen teorías de la comunicación:

Si hablamos de campo, necesariamente tenemos un enorme conjunto de teorías, no articuladas entre sí, relativas a los varios saberes que ahí se encuentran. Pero si hablamos de disciplina, evidentemente tendremos que ser más rigurosos, pues, antes que todo, tendremos que estar en condiciones de reconocer una teoría de comunicación: ¿qué es lo que hace que una teoría sea teoría de la comunicación? (p. 127).

En ese contexto, nos ocuparemos de reflexionar sobre las teorías de la comunicación no solo desde sus incidencias para el campo mismo, sino desde su enfoque como práctica educativa, donde se proyectan tanto docentes como estudiantes, sobre aquello que Marta Rizo (2012) denomina "el arduo trabajo de reflexión en torno a la formación en comunicación" 
(p.15). El escenario generalizado es el de un ejercicio docente volcado, casi exclusivamente, hacia una formación profesionalizante, aplicada y práctica de la comunicación.

Por ello, aquí nos proponemos: 1) recoger algunos abordajes más relevantes que han existido sobre la producción teórica en comunicación; 2) contrastar diferentes tradiciones metadiscursivas sobre el campo de las teorías de la comunicación; 3) mostrar las paradojas vigentes en contraste con lo que normalmente se asume en la práctica docente e investigativa, y 4) algunas consideraciones prospectivas sobre lo referente a la producción teórica en/sobre comunicación que se avizoran en la segunda década de 2000.

\section{Abordajes diversificados sobre la producción teórica en comunicación}

El desarrollo de las ciencias sociales en el siglo XX ha dado lugar a una verdadera explosión de teorías y literatura infinita, en una atmósfera de presiones culturales, históricas y políticas. Así desde la perspectiva de los núcleos problemáticos en las ciencias sociales, se reconocen hoy básicamente tres problemas, que nos limitamos tan solo a enunciar. Primero, el problema del reduccionismo planteado desde la absolutización de alguno de los diversos ejes epistemológicos de las ciencias sociales, bien sea el eje de la ciencia rigurosa, o el de la biología, o el eje de la cultura y la historia, cada uno tratando de exclusivizarse con lo cual genera una confusión. Segundo, el problema de denominación y clasificación de estas ciencias, el cual se mantiene en la medida en que estas ciencias ( ¿o disciplinas?) busquen su autonomía y logren su autocomprensión. En ese sentido, por ejemplo, Jean Piaget no acepta distinguir entre ciencias sociales y ciencias humanas, dado que todos los caracteres del hombre se ponen en juego en los fenómenos sociales. Y, finalmente, el problema del sentido, como el problema, categoría y preocupación fundamental de las ciencias sociales. Problema que va desde el dualismo entre ciencias de la naturaleza y ciencias del espíritu, pasa por el objetivismo en ciencias sociales, y llega hasta la confrontación entre la teoría analítica de la ciencia y la teoría de autoimplicación dialéctica y hermenéutica del sujeto en el objeto (Sierra, 2002, pp. 82-92). 
El siglo XX ha rebasado la concepción determinista clásica de las ciencias naturales propia de los siglos XVII a XIX, fundada en la exactitud y en la precisión predictiva. Se ha impuesto un enfoque probabilista y relativista que reconoce en las ciencias naturales la inexactitud, la imprecisión, el indeterminismo, la incertidumbre, la ambigüedad misma de los fenómenos naturales. En la reflexión actual, prevalece el postulado de la complementariedad entre ciencias naturales y ciencias sociales y humanas; es decir, se acepta la aportación de la historia y la sociología de la ciencia para la reconstrucción racional de las teorías científicas. "De ahí que nuestras certezas del pasado no puedan seguir guiando nuestras acciones, pensamiento o procesos en el presente, sobre todo porque es precisamente ese presente el que las ha puesto en duda" (Wallerstein, 2005, citado en Vidales, 2011, p. 39).

Como sostiene Wallerstein (2001), las ciencias sociales han padecido desde su nacimiento una definición y un estatuto ambiguos, con borrosos límites disciplinarios. En su perspectiva, el universalismo y el particularismo de las disciplinas no son necesariamente opuestos; todas las pretensiones disciplinarias absolutistas reduccionistas entran ahora en discusión. Las complicaciones en las ciencias sociales no han sido solo de orden epistemológico, sino también de organización social de los saberes en las universidades, sus posteriores divisiones en departamentos, facultades y de las prácticas de investigación, docencia y formación de los cientistas sociales. Queda claro que la división tripartita entre ciencias naturales, ciencias sociales y humanidades ya no es tan evidente como parecía serlo. Por ello, desde finales de la década de 1960 para acá, el desafío y la demanda general cada vez mayor es para "abrir las ciencias sociales", a lo cual busca responder la Comisión Gulbenkian en su documento sobre la reestructuración de las ciencias sociales (Wallerstein, 2001). ${ }^{3}$ Es precisamente lo que ha querido subrayar al cuestionar la legitimidad divisoria entre "las dos culturas" y la triple partición entre ciencias naturales, ciencias sociales y humanidades. No hay razones válidas para seguir alimentando monopolios en determinadas zonas de conocimiento (Wallerstein, 2001, p. 106; 2005, p. 28).

3 A este propósito respondió la Comisión Gulbenkian para la Reestructuración de las Ciencias Sociales en 1996, con Abrir las ciencias sociales (2001), bajo la dirección de Immanuel Wallerstein. 
En la perspectiva de Wallerstein (2001), entramos en el siglo XXI en una atmósfera nueva de producción de conocimiento que tiene vastos alcances para el análisis de las ciencias sociales. Por ende, tanto la importancia del análisis de sistemas complejos, del cual se ocupan las actuales "ciencias de la complejidad", como el creciente dinamismo de los "estudios culturales", desafiando con sus proyectos culturalistas todos los paradigmas teóricos existentes, han contribuido poderosamente a una visión menos contradictoria en los múltiples campos de conocimiento y a una reestructuración más abierta de todas las disciplinas, lo cual corresponde hoy a un movimiento transdisciplinario que adquiere cada vez mayor vigor (pp. 85-86).

En ese horizonte, sabemos que si bien existe un consenso generalizado entre investigadores y docentes de teorías de la comunicación sobre la emergencia a comienzos del siglo XX de estos estudios, como sinónimo de envío y recepción de mensajes, estrechamente asociados a los medios, no sucede lo mismo con relación a la configuración y sistematización de su corpus conceptual materializado en las llamadas teorías de la comunicación. Sobre esto se han dado diversas maneras de entender y explicar tal denominación.

La comunicación emerge como campo académico en los albores del siglo XX, en un escenario histórico marcado por la reorganización e institucionalización de saberes, pero ganando rápidamente una reconocida centralidad, caracterizada en buena parte como una práctica específica, por su organización como espacio académico orientado a comprender y definir sus límites y por la tendencia marcada hacia la interdisciplinariedad. En tal sentido, Rizo (2010) caracteriza de manera sintética la situación en estos términos:

\footnotetext{
El espacio académico de la comunicación es concebido de forma simultánea como campo profesional y práctico de formación de profesionales de los medios de difusión y como campo de conocimiento interdisciplinario con un objeto de estudio amplio en el que caben muchos fenómenos, la comunicación, susceptible de ser mirada desde disciplinas muy diversas (p. 1).
} 
En recientes trabajos, Vidales (2010a, 2010b, 2011) constata, y esa es una parte de su tesis central, que a medida que el campo de estudio de la comunicación se ha ido institucionalizando, se ha generado a la vez cierto relativismo teórico y conceptual. En su opinión,

[...] la generalización de los marcos epistemológicos o la inexistencia de éstos han producido una suerte de relativismo conceptual donde un concepto, una proposición o un acercamiento metodológico son considerados principios teóricos, teorías de la comunicación. A todo se le llama teoría pero en muy pocos casos se pueden distinguir con claridad la existencia de sistemas conceptuales (pp. 28-29).

Su aporte retrospectivo nos lleva a comprender la comunicación como un campo que ha pasado a ser considerado desde un elemento de organización de lo biológico/social (Sebeok, 2001; Martín Serrano, 2007; Piñuel y Lozano, 2006), un principio de la complejidad y de los procesos cognitivos (Aguado, 2003), hasta un espacio disciplinar (Fuentes, 1998a; Galindo y Luna, 1995). El movimiento más reciente ha sido el de su institucionalización, su incorporación como oferta académica en la vida social, paso que para algunos ha sido el más costoso (Peters, 1986 y 1999).

Cada vez, según Vidales (2010), resulta más evidente la síntesis de la discusión que ofrecía John Durham Peters (1989) a finales de la década de 1980; es decir que la comunicación ha sido definida administrativamente, pero no conceptualmente, mostrando así un vacío teórico en la definición de la comunicación como objeto distinto. Se pone así de presente un fuerte desequilibrio entre la producción teórica y la práctica de investigación.

El hecho es que se ha evidenciado una muy precaria autorreflexión sobre los propios marcos epistemológicos y los propios procesos de producción de conocimiento y los supuestos ontológicos que subyacen a las prácticas de investigación en comunicación. Raras veces se ha dedicado tiempo para analizar y “observar la propia observación” en un segundo orden. Haber volcado su mirada casi íntegramente sobre el mundo social ha ido en detrimento de una construcción más específica sobre las particularidades de los procesos que constituyen la comunicación como conocimiento científico particular. 
Resulta ilustrativo e interesante seguir aquí a Vidales (2011) en su recorrido crítico sobre las principales tendencias en este debate. Desde la perspectiva de Shepherd, John y Striphas (2006) y, dado el desequilibrio entre la investigación teórica y la llamada investigación aplicada, lo que existe es un "pluralismo teórico indiferenciado" o un "relativismo teórico". James Anderson (1996), J. Bryant y D. Miron (2004) ${ }^{4}$ sostienen que muchas de las así llamadas teorías de comunicación corresponden en realidad a propuestas axiomáticas o esquematizaciones de sistemas conceptuales de otras disciplinas a propósito de la comunicación. Por otro lado, Shepherd, John y Striphas (2006) están en contra de un pluralismo teórico indiferenciado; insisten en la necesidad de una jerarquización entre las teorías, dado que una cosa es su construcción y otra su aplicación. No obstante, se admite la existencia de un pluralismo de productos que se presentan como teóricos y su reproducción tiende a normalizar la producción teórica.

En igual sentido de crítica a la construcción teórica en el campo de la comunicación argumentan teóricos como Craig (1999), Shepherd, John y Striphas (2006), Krippendorf (1994), Carey (1989), entre otros.

De modo particular, para Carey (1989), dada la obviedad de la experiencia cotidiana de comunicación, no obstante, es sobre lo que menos se reflexiona a fondo; por consiguiente, "los modelos crean lo que nosotros ingenuamente creemos que representan, por eso algunos se convierten en instituciones sociales" (citado en Vidales, 2010a, p. 15).

Históricamente ha habido, tal vez, más debate sobre la comunicación como disciplina que sobre la producción teórica en los estudios de comunicación. Más adelante retomaremos este asunto desde la perspectiva de Martino (2001).

4 Vale la pena retomar esta cita 2 que hace Vidales del estudio de Bryant y Miron (2004), donde muestran que "la naturaleza del uso de las teorías en el campo de estudio de la comunicación se restringe a una mera referencia, dado que en 1,806 artículos (576 relacionados con la comunicación de masas) analizados en tres revistas importantes (Journalism \& Mass Communication Quarterly, Journal of Communication y Journal of Broadcasting \& Electronic Media) encontraron 1,393 referencias hechas a 604 teorías diferentes. De las teorías encontradas, los autores reconocen que $48 \%$ de ellas fueron usadas como mera referencia (citado en Vidales, 2011, p. 13). 
Por su parte, el teórico estadounidense, de la Universidad de Colorado (Boulder), Robert T. Craig (1999), en su trabajo "Ferment in the field", publicado originalmente en el Journal of Communication de 1983, complementado más tarde con "The future of the field" (1993) y "Communication theory as a field" (2008), en la International Encyclopedia of Communication, sostiene que el asunto de la comunicación como disciplina ha sido debatido desde la década de 1980 y que cada vez se recupera para incorporar nuevas perspectivas sin lograr llegar todavía a algún consenso sobre un núcleo teórico y una epistemología científica rigurosa sobre este campo. El hecho es que sigue siendo difícil una "visión pluralista sobre el diálogo de paradigmas" y los intentos por definir un núcleo teórico disciplinar que responda al pluralismo del campo (Craig, 2008).

De esa forma, para Craig, mientras unos están en favor de la constitución del estatus disciplinar del campo, otros están en abierto rechazo, manteniendo la fragmentación de aquel. Más que una sola teoría de la comunicación, lo que en verdad existe es un conjunto de prácticas metadiscursivas con implicaciones para las prácticas de comunicación, a las que llama "rutas de la incoherencia", por las cuales se produce un juego de interpelación autorreferencial entre teorías referidas a la consumación de las teorías en las prácticas de comunicación. Su propuesta, apenas enunciada, frente a la incoherencia teórica, es la de elaborar una matriz general que, en vez de centrarse en modelos transmisionistas o interpretativos, los supere e incluya múltiples visiones sobre la comunicación, un espacio a modo de "metamodelo" o "modelo de segundo orden", donde los distintos modelos, enfoques, perspectivas teóricas, puedan interactuar.

Es decir, como lo plantea Vidales (2011), y se enunciaba más arriba, se trata de un gran desequilibrio entre la investigación teórica y la investigación aplicada, lo cual conduce a un relativismo teórico entre dos rutas posibles: la consideración de la comunicación como principio explicativo y la consideración de la comunicación como disciplina práctica, con entrecruce de múltiples sistemas para presentar y representar la realidad. 
Pasada ya la primera década de 2000, la perspectiva de Craig (2008), compartida por muchos otros teóricos, sigue siendo la de una desarticulación entre la investigación de la comunicación interpersonal y masiva, al igual que la falta de consenso sobre un núcleo teórico epistemológico sobre el campo. Es decir, compaginar un núcleo teórico disciplinar con el pluralismo de un campo en constante transformación (Craig, 2008). En ese contexto, es necesario vincular también las problemáticas actuales que han emergido en los procesos de producción teórica sobre la comunicación, las que plantean los procesos de formación académica en este campo.

Por otro lado, en argumento planteado por Donsbach (2006), aunque la investigación en comunicación se ha multiplicado en los últimos treinta años, no obstante la identidad disciplinar se diluye en justificativas "integrativas", "interdisciplinarias", "sinópticas" que en nada aportan a la construcción de una identidad específica. Porque se siguen importando marcos teóricos de otras disciplinas para investigar problemáticas específicas de comunicación. En tal sentido, Donsbach (2006) sostiene: si bien la investigación sobre los procesos de comunicación ha permitido acumular una buena dosis de evidencia empírica, también es preciso reconocer que se ha sufrido de una creciente "erosión epistemológica" promovida por los desarrollos dentro y fuera del campo de estudio. De hecho, se puede seguir construyendo conocimiento empírico, pero la base reflexiva constitutiva del campo seguirá siendo difusa y poco clara. En su opinión,

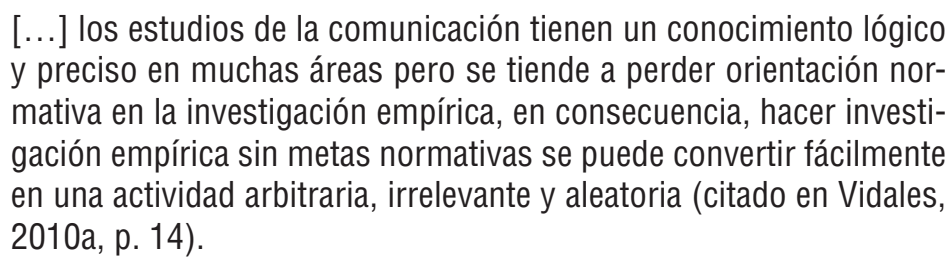

En contraposición con la postura de Craig, está la del danés Brier (2008), quien sostiene que los problemas de la dimensión conceptual de la comunicación no tienen que ver únicamente con su dimensión práctica, sino con la producción de conocimiento en el propio campo. Se trata de una práctica de investigación como un tipo particular de práctica comunicativa que apunta a una teoría unificada. La propuesta de Brier, a partir de la 
cibernética de segundo orden y la semiótica, es la de plantear el desarrollo de nuevos conceptos para entender los sistemas sociales, tales como redes autoorganizadas, redes autorreproducidas, es decir, hablar desde el punto de vista de "significados conjuntamente actualizados" en los sistemas sociales. Se trata, según Vidales, de la propuesta de una cibersemiótica como "visión interdisciplinar que integra distintos marcos en un nivel metadiscursivo que le da nacimiento a una visión diferente no sólo de la vida y los procesos cognitivos, sino de la comunicación y su construcción epistemológica" (citado en Vidales, 2011, pp. 33-35).

Desde otra perspectiva, Anderson (1996), a propósito de la/s teoría/s de comunicación, analiza los componentes que debe tener toda teoría, y, por supuesto, deben estar implicados en cualquier teoría de la comunicación. Su propuesta explora los que considera componentes de construcción de toda teoría: componente ontológico, epistemológico, praxeológico y axiológico. Es decir, toda teoría debe tener un objeto al centro de su explicación, una forma explicativa, un método para relacionar la evidencia con las afirmaciones que se hagan de ella, explicaciones características dentro de un ámbito de interpretación y una consecuencia de valor. Sin embargo, Anderson llama la atención sobre la construcción de sistemas conceptuales en contextos teóricos diferenciados donde es preciso reconocer que "la teoría no es sólo un conjunto de proposiciones textuales, así denominadas, sino prácticas continuas de comunidades intelectuales [... ] sobre las cuales se desarrollan procesos de aprendizaje" (citado en Vidales, 2010a, pp. 49 y 50). Así, de un conjunto de prácticas para la producción de conocimiento se pasa a derivar la reproducción de afirmaciones aceptables, acuerdos en la construcción de sistemas conceptuales, organizados en marcos jerárquicos diferenciados que se asumen sin mayor cuestionamiento. Es precisamente el caso de un estudio de Anderson sobre siete libros de los cuales extrae 249 referencias a teorías de la comunicación, sintetizadas en 18 teorías generales $^{5}$ (Vidales, 2010a, p. 51), que buscan normalizarse, es decir, buscar la identificación con algún principio teórico precedente, con la intención de validarse y ganar reconocimiento (citado en Vidales, 2011, p. 20).

5 Teoría de la disonancia cognitiva, teoría de la reducción de la incertidumbre, modelo retórico sensitivo, constructivismo, gestión coordinada de la teoría del significado, teoría narrativa, análisis de cultivo, usos y gratificaciones, agenda Setting, la espiral del silencio, estructuración y teoría social, teoría de la acción social (Anderson, 1996). 
En ese sentido, dada la alta diversidad del campo en métodos, teorías y objetos de estudio, el interrogante planteado por Craig sigue teniendo plena vigencia, es decir: "¿Qué es, si es que lo hay, lo que une al campo como una entidad coherente? (2008, p. 675). Su pregunta apunta a la naturaleza de ese foco común que para él se trata, más allá de los problemas que genera una especificidad epistemológica, de considerar la comunicación como una práctica cultural específica significativa de la que se derivan metadiscursos referidos a prácticas metadiscursivas, es decir, formas de referirse a la comunicación con propósitos prácticos. Y, en opinión de Craig, es sobre esas propias prácticas metadiscursivas a las que se ha dado en denominar el campo de las teorías de la comunicación (Vidales, 2011, p. 21).

No es de extrañar, entonces, que desde los orígenes mismos del campo de la comunicación, sus prácticas investigativas revelen una enorme diversidad, con la convergencia de varias disciplinas, importando conceptos, métodos provenientes de las ciencias sociales, las humanidades, incluso de las ciencias naturales y la ingeniería, pero sin la integración en un cuerpo coherente de conocimiento.

Existe por lo tanto el reto epistemológico de enfrentarse, primero, a cierta excesiva acumulación de saberes que atañen a la comunicación como objeto material de estudio; y segundo, evidentemente este empeño ha obligado a los profesores de la materia a repasar los saberes que la biología, la psicología, la lingüística, la filosofía, la historia y la sociología aportan al estudio de la comunicación animal, de la comunicación humana y de la comunicación social; a veces, también se plantea examinar tales aportaciones, procurando completarlas hasta constituir un campo de estudio: el de la comunicación. No obstante, este empeño obligaría también a plantearse si existe un paradigma disciplinario susceptible de proporcionar un nuevo enfoque capaz de integrar y reorganizar todos los saberes sobre la comunicación. ¿Se habría llegado así a poner las bases de una nueva "disciplina” científica? ¿Y cómo debería llamarse? ¿Teoría de la comunicación? 
En la línea de Piñuel (2010), "las nociones de teoría, así como las nociones de objeto de estudio, campo de conocimiento y de prácticas que revisan el saber se usan a veces bajo requisitos de diferente rigor" (p. 18).

La propuesta de Craig (2008) señalada arriba muestra que se trata de cambiar de la pregunta de “¿cómo es posible la comunicación?” para la pregunta “¿cómo se consuma la comunicación en la práctica?”, y, según Vidales (2011), a “icómo la comunicación podría ser?” (p. 25). Así, en síntesis, la postura de Craig apunta a reconstruir la teoría de la comunicación como un metadiscurso teórico que fundamenta el potencial metadiscursivo práctico de la comunicación en la vida cotidiana.

Desde una perspectiva latinoamericana, existen aportes muy significativos que no pueden pasarse por alto como los de Fuentes (1999), Martino (2001), entre otros. Aquel a propósito de la institucionalización del campo de la comunicación, centra su reflexión en tres grandes problemas por resolver: el de la legitimación, el de la institucionalización y el de la profesionalización de los estudios de comunicación. Sobre la legitimación del campo, este autor sostiene que en un análisis epistemológico del campo de la comunicación deben incluirse en el debate abierto no solo los discursos propios del campo, sino todos los factores sociopolíticos, ontológicos, éticos, organizativos y sociales. "Por lo tanto, la actual situación del campo académico de la comunicación requiere una articulación muy delicada de reflexión epistemológica con análisis sociológicos y ético-políticos de los intrincados procesos de su legitimación institucional, pues, en el fondo, es una lucha ideológica que cruza por la territorialización" (citado en Vidales, 2010a, p. 42).

En relación con la institucionalización de este campo de estudios, Fuentes (1999), apoyado en Jesús Martín-Barbero, afirma que conviene revisar los fundamentos y las estructuras institucionales en las que se sostiene e impulsa la disciplinarización del campo.

[...] los procesos de institucionalización del campo académico de la comunicación en América Latina han desarrollado, mantenido y reforzado una desarticulación múltiple [...] El principal es confundir, 
como lo ha sintetizado Jesús Martín-Barbero, las condiciones de desarrollo del o los mercados profesionales, con las exigencias de un campo intelectual. La formación profesional, al extremar sus rasgos disciplinarios, se fragmenta 0 especializa funcionalmente, aunque deje un residuo creciente de comunicadores disfuncionales. La teoría no puede segmentarse así sin perder poder explicativo (citado en Vidales, 2010a, pp. 44-45).

Finalmente, sobre la profesionalización del campo de la comunicación, Fuentes (1999) apoyado en la teoría de la estructuración de Giddens (1995) propone:

[...] es mediante la formación en los posgrados de agentes académicos competentes para producir socialmente sentido sobre la producción social de sentido, que el campo académico de la comunicación puede no sólo reorientarse para avanzar en su legitimación, sino que podrá generar explicaciones más plausibles y orientadoras de las transformaciones en curso en el mundo y del papel que los sistemas y prácticas de comunicación tienen en esas transformaciones, y basar su legitimación en esta competencia académica más que en su competitividad institucional (citado en Vidales, 2010a, p. 45).

Desde otro frente, Martino (2001) parte de un cuestionamiento previo: “¿Existen teorías de la comunicación?”. Pareciera que todos damos por supuesta la "creencia", y llegásemos incluso hasta la certeza, de que en realidad tales teorías existen y actuamos en consecuencia lógica con todas sus derivaciones, pese a todos los inconvenientes, dificultades y obstáculos que se den en su definición o caracterización.

Si bien en la década de 1940 se hablaba más de investigación en comunicación en vez de teorías de comunicación, según Martino la institucionalización de los estudios de comunicación en posgrados, acompañada de la proliferación de producción intelectual dedicada al tema, al igual que una práctica sistemática de producción de teorías, llevaron a que la hipótesis se volcase para un primer plano central. Se empezaron a generar, a partir de la década de 1960, libros de teorías de la comunicación, que daban acceso a ese campo de conocimiento teórico, y así se fue abriendo paso a dicho reconocimiento. 
Antes de la década de 1960 difícilmente se podía hablar de teorías de la comunicación. Las más reconocidas, tales como la teoría hipodérmica, el esquema de Lasswell, la teoría crítica, la Escuela de Chicago, aunque fueron elaboraciones importantes en su momento, y con frecuencia reconocidas como clásicas en nuestro campo de conocimiento. Sin embargo, dichas teorías curiosamente nunca reivindicaron para sí mismas el título de teorías de la comunicación; al contrario, permanecieron ligadas a su campo disciplinar de origen (Martino, 2001, pp. 16-17). La atribución como tales provino del campo de la comunicación, que ya en la década de 1960, para consolidar un sector de producción y publicación, comienza a agruparlas y tratarlas como campo específico de estudio. Asílo ratifica este mismo autor:

En otros términos, es la sistematización de las teorías -y no simplemente su producción - la que da visibilidad y forma a la idea de teorías de la comunicación. Aquellas teorías que rápidamente vienen a nuestro espíritu, aquellas que podemos citar con más facilidad, se adquirieron a través de esa literatura. No solamente porque es a través de esos libros que entramos en contacto con ellas, sino porque es a partir de ese tipo de obras que se da — pese a la fragilidad de todo el proceso- el reconocimiento de algunas teorías como teorías de la comunicación. Nuestra creencia se encuentra totalmente asociada a esta literatura (p. 18).

Muchos de los libros y artículos que circularon en ese entonces no discutían el problema de la autonomía de la comunicación como área de conocimiento, al contrario, "introdujeron la idea de teorías de la comunicación y subrepticiamente, terminaron induciéndonos a creer en su existencia" (p. 19). ${ }^{6}$ Terminaron reforzando la creencia en un área interdisciplinar, que se expandió rápidamente para poder posicionarse de modo relativamente adecuado en el concierto de las ciencias sociales.

En tal sentido, la perspectiva de Martino (2001) subraya que entender lo que es teoría de la comunicación es un problema que no puede prescindir de una discusión epistemológica, con visión crítica sobre la constitución

6 Cabe anotar aquí que Martino llevó a cabo una investigación sobre el estado actual de las teorías de la comunicación, comparando los contenidos de los libros en lengua española de teorías de la comunicación, tras lo cual encontró un conjunto de teorías muy dispares entre sí, sin ningún criterio específico de selección, sin definir un concepto de teoría y tampoco de comunicación, y que, por consiguiente, no tenemos una idea muy precisa de lo que es la teoría de la comunicación (2001, pp. 20-21). 
del saber comunicacional. Muchos investigadores han eludido los problemas relacionados con esa discusión y han buscado otras alternativas más aplicadas a territorios empíricos, consolidando así subáreas de la comunicación demarcadas por las actividades profesionales (periodismo, publicidad...), y por las interfaces con otras disciplinas (lingüística, sociología, psicología ...), o por los grandes temas de interés social (salud, organizaciones... ), en masa, grupal o individual. "Descuidar la cuestión epistemológica, o peor, tratar de sustituirla por otro tipo de abordaje, sólo puede llevarnos a mantener el estado de confusión, donde no puede aparecer el significado de teorías de la comunicación" (p. 26).

Este autor insiste en tener en cuenta dos preceptos básicos empleados en epistemología de las ciencias humanas: primero, en relación con el fenómeno, no se trata de un objeto empírico, sino construido a través de una elaboración teórica; y segundo, una teoría solo puede ser considerada teoría de la comunicación si respeta el precepto de la centralidad del fenómeno comunicacional (p.28). De igual forma que para el economista la centralidad de los fenómenos económicos gira alrededor del mercado, el comunicólogo debe explicar la realidad humana a partir de los fenómenos comunicacionales. Toma a la comunicación no necesariamente como causa, sino como factor central para la comprensión de esos fenómenos.

Una teoría se caracteriza como pertinente para una disciplina si está referida específicamente a un área de conocimiento. Según Martino, el gran problema que hemos tenido ha sido sostener el concepto de la existencia de unas teorías de la comunicación completamente desconectadas de la idea de fundamentación de un área de conocimiento. De ahí el descuido de pensar la pertinencia de tales teorías en relación con su área de conocimiento.

En concepto de este autor, nunca hubo una preocupación seria por distinguir entre teorías "sobre" comunicación y teorías "de" la comunicación, lo cual generó total ausencia de criterios de pertinencia en relación con el área de conocimiento de la comunicación (p. 30). De la supuesta conver-

7 Según Martino, la producción de libros de teorías sobre comunicación, que se inició en la década de 1960, nos generó la certeza de que existen teorías de la comunicación, sin prestar la más mínima atención a los matices de significado representados por las dos expresiones (2001, p. 38). 
gencia de investigación sobre procesos comunicacionales, en perspectiva interdisciplinar, se dio la automática inferencia y generalización de equivalencia a una disciplina.

En síntesis, este autor apunta a subrayar que las teorías no son independientes de un área de conocimiento; resulta completamente contradictorio hablar de teorías de la comunicación, sin referencia a una disciplina.

Lo que está en juego es la autonomía de esa área de estudios cuestionada en su capacidad de generar conocimientos... léase conocimientos propios, producidos a partir de las teorías de la comunicación [...] De ahí la situación extremadamente sui generis de la Comunicación como un campo bien desarrollado en el plano institucional (instituciones educativas, formación profesional, revistas especializadas, asociaciones científicas), sin deberles nada a las disciplinas más desarrolladas, excepto una única cosa: las teorías (pp. 37 y 39 ).

El panorama ciertamente es el de un debate abierto sobre un asunto de doble implicación: tanto sobre la constitución y especificidad del campo mismo de la comunicación, como sobre la posibilidad de construcción de referentes teóricos consistentes, que dinamicen procesos de investigación en comunicación en diferentes contextos. Sin duda, han sido numerosos y valiosos los intentos por replantear tanto los procesos de producción teórica en comunicación como los de una matriz organizativa general que apunte a la construcción de bases comunes de una ciencia de la comunicación. Los autores y sus perspectivas metadiscursivas son múltiples y diferenciadas sobre el campo de las teorías de la comunicación, y de ello nos ocuparemos en el siguiente apartado.

\section{Tradiciones metadiscursivas sobre el campo de las teorías de la comunicación}

Si bien el propósito de este texto no es el de defender una postura que abogue por imponer una matriz teórica organizativa general, tampoco se puede desconocer que el campo de la comunicación, en su breve historia, haya tenido lo que Vidales (2011) nombra "rutas genealógicas", y Craig (2008) 
"tradiciones metadiscursivas" que, a modo de construcciones teóricas específicas, se han ido acumulando, ganando alguna consistencia y contribuyendo a configurar algunas bases teóricas comunes para el campo. No obstante, estas bases teóricas, por su focalización sobre procesos empíricos, es preciso ubicarlas en el tipo de construcción o formulación teórica que Merton (1949) llama "teorías de rango o alcance medio" (middlerange theories).

El sociólogo estadounidense Robert Merton en $1949,{ }^{8}$ en su obra Teorías y estructuras sociales, refiriéndose a la teoría sociológica, y en contraste con las teorías generales de los sistemas sociales de carácter más totalizador, hace un planteamiento metodológico relacionado con las que denomina "teorías de rango medio" o "de alcance intermedio" (middle-range theories). Dada la abundancia de teorías sociológicas explicativas de los fenómenos sociales y la enorme dificultad de encontrar una teoría que sirviera como "regla general", Merton recomendó elaborar "teorías de alcance intermedio" con un alcance limitado y proporcional, generadoras, por tanto, de hipótesis, categorías, relaciones y prospecciones aplicadas al fenómeno concreto que investigan. Este tipo de teorías, aunque incluyen abstracciones, sin embargo, están bastante cerca de los datos y la realidad empírica. Pero con ellas no se pretende la búsqueda de una teoría totalizadora de carácter universal, sino la focalización conceptual de un tipo de problemas empíricos específicos. Aclara Merton que los problemas de investigación y los métodos para abordarlos están ligados a los intereses y las experiencias de los investigadores sociales y de quienes patrocinan su actividad. Su propuesta es sobre la teoría no como contemplación, sino como sistema orientador de acción social, con lo cual instaura un nuevo paradigma que tuvo su pleno auge con el empírico funcionalismo estadounidense y la investigación en comunicación de masas.

En el campo de la comunicación, esos procesos de producción teóri$\mathrm{ca}$, por cierto bastante recientes, se fueron sucediendo a modo de referentes conceptuales para la investigación. Cabe aquí mencionar que autores

8 La edición original inglesa de esta obra apareció en 1973; la versión en castellano es de 1977. En 1949 publica Teoría y estructuras sociales. Sobre la obra de Merton también puede consultarse Orozco y Chavarro (2010, pp. 143-162). 
como Peters (1999), Martín Serrano (1990), Escarpit (1977), Mattelart (1997) reconocen que, a partir de la teoría matemática de la información de Shannon y Weaver (1948), la información pasó, en su momento, a ser el concepto constructivo unificador referencial que permitió comprender lo que es la comunicación, aunque la gran matriz epistemológica fuese la cibernética de Norbert Wiener (1960). "La comunicación fue un concepto capaz de unificar las ciencias naturales (el DNA como el gran código), las artes liberales (el lenguaje como comunicación), y las ciencias sociales (la comunicación como el proceso social básico" (citado en Vidales, 2011, p. 26).

En la perspectiva de Martín Serrano (1990), la información fue lo que garantizó la permanencia en su estructura diferenciada a organismos y organizaciones diversas ante fenómenos de cambio y transformación (citado en Vidales, 2011, p. 27).

No obstante el reconocimiento de que han gozado la teoría matemática y la cibernética en la historia de las teorías de la comunicación, no son estas las que más dinamizan los procesos de construcción teórica y aplicación empírica. Han sido otras tradiciones las que, desde una mirada subjetiva de diferentes autores y en perspectiva metadiscursiva, han organizado el campo de las teorías de la comunicación a modo de referentes constructivos unificadores:

En este sentido, siguiendo a Vidales (2011), Craig (1999) reconoce siete tradiciones metadiscursivas, que darían cierta organización teórica al campo de la comunicación: 1) tradición retórica (comunicación como el arte práctico del discurso); 2) tradición semiótica (comunicación como mediación intersubjetiva de signos); 3 ) tradición fenomenológica (comunicación como experimentación del otro); 4) tradición cibernética (comunicación como procesamiento de información); 5) tradición sociopsicológica (comunicación como expresión, interacción e influencia); 6) tradición sociocultural (comunicación como reproducción del orden social), y 7) tradición crítica (comunicación como reflexión discursiva). 
Por su parte, Alsina (2001) las organiza en torno a tres grandes perspectivas: 1) perspectiva interpretativa (Escuela de Palo Alto, interaccionismo y construccionismo); 2) perspectiva empírico-funcionalista, y 3) perspectiva crítica (Escuela de Frankfurt, economía política y estudios culturales).

En el contexto latinoamericano, Rizo (2006), en su estudio sobre 15 manuales de comunicación, identifica 120 nombres de las allí llamadas teorías de la comunicación (citado en Vidales, 2010a, nota 13, p. 51).

El investigador boliviano Erick Torrico (2004) sostiene que "las teorías son horizontes de sentido más o menos limitados en su cobertura de $v i$ sibilización y decibilidad de lo real” (p. 79). Considera que toda teoría debe estar históricamente situada, y para ello establece periodizaciones económico-políticas en las cuales se situarían en equivalencia las matrices teóricosociales prevalentes, a las que estarían estrechamente correlacionados los periodos teórico-comunicacionales más relevantes. A su vez, a cada periodo teórico-comunicacional le correspondería un determinado abordaje del proceso comunicacional (tabla 1 ).

\section{Tabla 1. Periodos teórico-comunicacionales}

\begin{tabular}{|c|c|c|c|}
\hline $\begin{array}{l}\text { Periodo 1: expansión } \\
\text { capitalista (1914-1946) }\end{array}$ & $\begin{array}{l}\text { Periodo 2: guerra fría } \\
\quad(1946-1991)\end{array}$ & $\begin{array}{l}\text { Periodo 3: globalización } \\
\qquad(1991-2001)\end{array}$ & $\begin{array}{l}\text { Periodo 4: destrabamiento } \\
\text { hegemónico global (2001-) }\end{array}$ \\
\hline $\begin{array}{l}\text { Matriz teórico-social: } \\
\text { estructural, funcionalismo, } \\
\text { dialéctica crítica. }\end{array}$ & $\begin{array}{l}\text { Matriz teórico-social: } \\
\text { estructural, funcionalismo, } \\
\text { estructuralismo, dialéctica } \\
\text { crítica. }\end{array}$ & $\begin{array}{l}\text { Matriz teórico-social: } \\
\text { estructural, funcionalismo, } \\
\text { posestructuralismo, } \\
\text { sistemismo. }\end{array}$ & $\begin{array}{l}\text { Matriz teórico-social: } \\
\text { posestructuralismo, } \\
\text { sistemismo, dialéctica } \\
\text { crítica. }\end{array}$ \\
\hline \multirow[t]{2}{*}{$\begin{array}{c}\text { Periodo teórico- } \\
\text { comunicacional: } \\
\text { difusionista (1927-1963) }\end{array}$} & $\begin{array}{c}\text { Periodo teórico- } \\
\text { comunicacional: crítico } \\
(1947-1987)\end{array}$ & $\begin{array}{c}\text { Periodo teórico- } \\
\text { comunicacional: } \\
\text { culturalista }(1987-2001)\end{array}$ & $\begin{array}{l}\text { Periodo teórico- } \\
\text { comunicacional: } \\
\text { actual (2001- ) }\end{array}$ \\
\hline & & $\begin{array}{l}\text { Abordaje del proceso } \\
\text { comunicacional: político- } \\
\text { cultural, sociotécnico. }\end{array}$ & $\begin{array}{l}\text { Abordaje del proceso } \\
\text { comunicacional: socio- } \\
\text { técnico, político-cultural, } \\
\text { crítico. }\end{array}$ \\
\hline
\end{tabular}

Fuente: Modificado de Torrico (2004, pp. 99, 126-127, 129-136).

También Vidales (2010a) nos ofrece su bosquejo de la producción teórica en el campo de la comunicación, organizado en tres niveles: 
1. Nivel de legitimación: de una propuesta teórico-metodológica; aquí estarían todas aquellas obras introductorias al pensamiento comunicacional con determinadas construcciones conceptuales, sus propios recuentos históricos, que sirven para orientar la investigación y donde parecería legitimarse el estatuto científico de la comunicación.

2. Nivel crítico de organización: del campo de estudio en lo institucional dependiendo de su propio espacio territorial.

3. Nivel de la cientificidad: está dado por las discusiones sobre el estatuto científico de la comunicación. Cabe anotar que, de acuerdo con esta organización, pueden encontrarse autores y obras que caben en dos o más de los niveles mencionados. ${ }^{9}$

Y para finalizar esta panorámica, en afinidad con la propuesta de Torrico (2004), para Carrasco y Saperas (2013) el campo de la comunicación, a partir de los diferentes contextos históricos, ha evolucionado y formalizado tendencias y cambios teóricos. Plantean una relación estricta entre factores históricos, culturales, político-económicos y tecnológicos del contexto histórico con el desarrollo teórico de la investigación comunicativa, en medio de los cuales se han dado progresivas "mayorías de edad”. Los dos escenarios históricos prominentes previos de "mayoría de edad" serían: por una parte, el periodo de entreguerras, en especial la década de 1930; por otra, las décadas de 1960 y de 1970.

En el primero estaría el estructural-funcionalismo y la investigación de corte administrativo, con teorías explicativas parciales de alta eficacidad explicativa que han impuesto su hegemonía hasta la actualidad, en contraposición con otras propuestas alternativas circulantes en Europa, como la teoría crítica, el interaccionismo simbólico y las sociologías clásicas comprensivas. En el segundo, dada la aparición de la ciencia política y los nuevos paradigmas culturalistas, la investigación comunicativa se diversifica. Los nuevos marcos teóricos estarán asociados al estructuralismo, giro lingüístico, hermenéutica, estudios culturales, sociologías interpretativas y teorías de rango medio (Carrasco y Saperas, 2013, pp. 961-962).

9 El desarrollo ampliado de su propuesta organizativa puede verse en Vidales (2010b, pp. 56-61). 
La década de 1990 muestra un tercer escenario de "nueva mayoría de edad" en la investigación comunicativa. Se opera una mutación particularmente intensa que ha llevado los nuevos enfoques contemporáneos de la investigación comunicativa, dados los acontecimientos históricos vividos (caída del Muro de Berlín, fracaso del socialismo real, mundialización/globalización tecnológica, económica y política, creación de la red mundial de información internet). Estaríamos viviendo entonces lo que Beck, Giddens y Lash (2001) llaman "un proceso de modernización reflexiva".

A partir de la década de 1970 hasta la actualidad, no ha cesado el cuestionamiento sobre el estatuto científico de la actividad investigativa en comunicación y los distintos esfuerzos por una sistematización del campo comunicativo principalmente a través de revistas internacionales de referencia como Journal of Communication, ${ }^{10}$ y libros de gran influencia en el medio académico e investigativo. En el entorno académico europeo, dos textos han sobresalido como referentes clásicos de gran influencia sobre la sistematización del campo comunicacional: Mass Communication Theory, de Denis McQuail (2010) e Histoire des théories de la communication, de Armand y Michèle Mattelart (1997), influencia similar a la ejercida en los Estados Unidos por Milestones in mass communication research, de Shearon Lowery y Melvin Lawrence de Fleur (1995).

Según apreciación de Carrasco y Saperas (2013a, 2013b), en estas últimas décadas, el auge de la televisión y lo audiovisual, al igual que la consolidación progresiva de la web, han ido configurando una hegemonía estadounidense en el sistema comunicativo, enmarcados en un proceso creciente de globalización neoliberal, con incidencias marcantes para el devenir de la investigación comunicativa y de las ciencias sociales en general.

Sin duda, son muchos más los autores que realizan otras formas de agrupación teórica, y que no alcanzamos a mencionar aquí, pero que tienen igualmente su relevancia, como Scolari (2008); Galindo y el Grupo GUCOM (2008); Barret (2006); Sá Martino (2008, 2014); Sodré (2012);

10 Véase la investigación de Carrasco y Saperas (2013b) sobre papers referidos a teorías de comunicación, publicados en Journal of Communication (2008-2013). 
Ferreira, Hohlfeldt, Martino y de Morais (2010); Ferreira (2007); Vasallo de Lopes $(1999,2014)$, entre otros. Todo ello, a nuestro entender, es indicativo de que el campo tiene una dinámica pluriversa sobre producción teórica referida al campo comunicacional que intenta seguir el ritmo de las transformaciones socioculturales y tecnológicas contemporáneas.

\section{Paradojas vigentes: entre teoricismo y practicismo}

El rápido recorrido seguido hasta aquí sobre el pensamiento comunicacional nos permite constatar que en efecto este campo, en lo que atañe principalmente a su producción teórica, se mueve en una dinámica oscilatoria de carácter paradójico creciente.

Por su parte, Mattos (2005) sostiene que el campo comunicacional atraviesa en el escenario contemporáneo por uno de sus grandes desafíos: un proceso paradójico oscilatorio de transición y sobresaltos continuos, porque no es posible asegurar una ruptura definitiva con sus paradigmas clásicos asociados al funcionalismo estadounidense y a la teoría crítica formulada por la Escuela de Frankfurt, cuyos presupuestos, conceptos y categorías de análisis son remozados constantemente en el ejercicio docente e investigativo, pero que resultan muchas veces inadecuados para interpretar las mutaciones de la tecnocultura comunicacional globalizada.

Así, siguiendo a Vattimo (2000) y Lyotard (1987), las grandes narrativas como visiones explicativas del mundo están actualmente en crisis, y entre ellas habría que incluir ciertamente las ofrecidas por los medios masivos y los modelos teóricos fundacionales de la comunicación, precisamente por no dar cabal cuenta de la procesualidad multidimensional y global de los procesos comunicativos contemporáneos. Todo ello con implicaciones en la formación teórica en comunicación social y en la identidad de los sujetos implicados en el proceso académico (enseñanza-aprendizaje-profesores, investigadores y estudiantes de comunicación) (Mattos, 2005).

El planteamiento de Mattos propone dividir en tres grandes momentos que evidenciarían una creciente crisis de los paradigmas comunicacionales. 
El primero habría que localizarlo hacia finales de la década de 1970 como momento emblemático de la "crisis de las teorías de la comunicación", y la búsqueda por otros enfoques teóricos y metodológicos. Se realizó una revisión crítica de los principios y modelos clásicos de la comunicación exacerbados hasta entonces por el mediacentrismo y el empírico funcionalismo. Se manifestó en una disputa dicotómica entre profesores, investigadores y estudiantes de comunicación seguidores del enfoque de la sociología empírica estadounidense y aquellos seguidores del enfoque crítico de la Escuela de Frankfurt, por la hegemonía en el espacio académico, distanciándose de las realidades propias del espacio latinoamericano. Se configuró así, según Mattos, "una década caracterizada por grandes distorsiones en la formación teórica en Comunicación Social, agravada sobre todo, por la imposición de currículos mínimos y por la fragmentación dicotómica entre teoría/práctica en la formación teórico-profesional” (2005, p. 49).

El segundo momento (década de 1980) no solo ahondó y radicalizó la crisis de los modelos clásicos fundacionales de la comunicación, sino que sirvió para ver emerger nuevas perspectivas problemáticas y nuevas corrientes de estudio. En Latinoamérica, se dio el gran quiebre que daría un nuevo rumbo a la investigación comunicacional al proponer un descentramiento radical "de los medios hacia las mediaciones socioculturales", devolviendo el protagonismo activo al sujeto receptor, y abriéndose a nuevas problemáticas referidas a la mediación de productos televisivos, usos y apropiaciones de los medios por la cultura popular, lectura crítica de los medios, que llevaron a reconfigurar el campo comunicacional en toda la región. Este giro ha tenido vastas repercusiones tanto en la reconfiguración de los enfoques de enseñanza e investigación como en la capacitación de grupos y organizaciones sociales. Fue Jesús Martín-Barbero (1988) quien propuso una reforma sustancial en la enseñanza de la comunicación que hiciera hincapié no en los medios masivos de comunicación, sino en las mediaciones socioculturales, que reconociera al mismo tiempo la diversidad cultural y la pluralidad de procesos y prácticas cotidianas de comunicación. Para MartínBarbero (1988) debe superarse el modelo de enseñanza de la comunicación centrada exclusivamente en los medios, y en reproducir lo que hacen los medios convencionales y las prácticas profesionales formales, para abrirse 
a proyectos de mayor envergadura y complejidad sociocultural en los procesos y las prácticas populares de comunicación.

En las décadas siguientes no faltaron quienes cuestionaron la propuesta de Martín-Barbero, como Braga (2007), quien alerta sobre el peligro de diluir los estudios de comunicación en un abordaje cultural excesivamente amplio que generaría confusión entre instancias culturales, comunicacionales y extracomunicacionales. En consecuencia, se llega al final de la década de 1980 sin una delimitación clara tanto del objeto de estudio de la comunicación como de los modelos teóricos más apropiados para la formación del comunicador social. Por consiguiente, no se logra crear un referente sobre lo que es y de qué modo estudiar la comunicación, por lo cual proliferan nuevos abordajes en la enseñanza y la investigación en comunicación con diferentes denominaciones: "posmodernas", "actuales", “contemporáneas” (Mattos, 2005, pp. 48-51).

El tercer momento cubre la década de 1990 y el cambio de siglo, y refleja la comunicación como un campo de conocimiento de naturaleza inter-, multi- y transdisciplinar, tras lo cual evidencia en la comunidad de académicos y estudiantes de comunicación gran dificultad para trabajar con la convergencia de otros saberes, y efectuando muchas veces más yuxtaposición con otras disciplinas que interfaces productivas de la comunicación con otras áreas de conocimiento. A la par, surgen grupos de académicos que reivindican la autonomía y legitimación del campo teórico-epistemológico de la comunicación frente a otros campos de las ciencias sociales y humanas. Igualmente a estos últimos se contraponen sectores académicos que subrayan la importancia de los enfoques teóricos aplicados y profesionalizantes de la comunicación por encima de cualquier pretensión de reflexión epistemológica sobre el campo.

Con el cambio de milenio, aparecen nuevos referentes teórico-analíticos para el campo de la comunicación, apoyados en la proliferación de tecnologías infocomunicacionales que afectan todas las esferas de la vida social e individual que conciben la comunicación como una red de circularidad infinita con difusos actores comunicacionales. Es decir, un escenario 
contemporáneo donde prevalece cierta simplificación reduccionista alrededor de la llamada sociedad de la información y de la comunicación o de la sociedad red, que en forma de constataciones simplistas pueden desviar la atención de la observación analítica de la multidimensionalidad y complejidad de los nuevos fenómenos comunicacionales (Mattos, 2005, pp. 52-55).

\begin{abstract}
Se constata la adopción de posturas académicas reduccionistas y acríticas, que se expresan en discursos celebratorios sobre las prácticas comunicativas ancladas en los modernos sistemas mediáticos y tecnológicos, atribuyéndoles con frecuencia la determinación exclusiva de orientar la sociedad, la enseñanza universitaria, el pensamiento comunicacional. Esos modismos se incorporan en los contenidos programáticos de innumerables asignaturas de los cursos de comunicación, incluidas las Teorías de la Comunicación, con la pretensión de otorgarle "cientificidad" a los fenómenos empíricos (p. 53).
\end{abstract}

Mientras tanto, según Martino (2001), paradójicamente el campo comunicacional se ha ido construyendo como campo de conocimiento con un cuerpo multiforme y confuso de teorías de la comunicación, que nunca se ha preocupado por establecer la distinción — sobre algo tan esencial— entre teorías sobre y teorías de la comunicación; o sea, teorías que se ocupan de fenómenos comunicacionales en el sentido amplio y teorías propiamente comunicacionales, que se caracterizan por un cierto tipo de aproximación o recorte de la realidad. Las primeras, es fácil constatar, son provenientes de las más diferentes disciplinas (sociología, psicología, ciencias políticas...), mientras que la segunda expresión designa las teorías que constituyen una disciplina, un saber autónomo. Sin embargo, la existencia del componente de las teorías de la comunicación al igual que sus asignaturas afines, escaladas irregularmente, sigue manifestando una paradójica centralidad en los planes de formación profesional del comunicador social, que seguirá siendo objeto de debate permanente.

En síntesis, en el campo de la comunicación persiste un cruce donde las paradojas siguen vigentes, entre un "teoricismo" expresado en un relativismo teórico creciente que se fragmenta en múltiples modelos explicativos de índole epistemológica, ontológica o axiológica y un "practicismo" con una sobreoferta de principios conceptuales explicativos aplicados a prácticas 
concretas de la comunicación, las cuales tienen su repercusión más próxima, entre otros, en la falta de articulación entre enseñanza e investigación y el debilitamiento del estatuto teórico de la comunicación como nuevo espacio de conocimiento.

\section{Algunas consideraciones prospectivas}

Algunas consideraciones prospectivas acerca de la producción teórica en comunicación nos permiten avizorar hacia dónde se encamina el debate. La proliferación de congresos, coloquios, actos académicos en las últimas décadas en torno a la comunicación pone de manifiesto que en tales escenarios se socializan, cada vez en mayor proporción, trabajos de producción investigativa sobre fenómenos aplicados instrumentales de comunicación (media studies, communication studies o technological studies), con una clara primacía de los aspectos metodológicos sobre los propiamente teóricos, y muy pocos trabajos investigativos referidos a la constitución epistemológica del campo mismo de la comunicación. Pareciera, como dice Sodré (2012), que la comunicación en este nuevo milenio continúa siendo un campo "en apuros teóricos".

Se percibe a lo largo de esta última década una tendencia a seguir incentivando un modelo de investigación puramente instrumental, con una cierta degradación de la teoría como fin en sí mismo y un incremento en favor de las teorías de rango medio.

Es igualmente marcada la tendencia hacia una institucionalización internacional de la investigación comunicativa con estándares de medición, comparación y evaluación de la producción científica socializados mediante papers en actos académicos internacionales de comunicación. En el editorial de Communication Theory (2013, p. 8), Hanitzsch autoevalúa los papers de naturaleza teórica para establecer no solo una clasificación de autores teóricos más citados universalmente, sino también para mostrar, de manera sintomática, un esquema regulativo de la actividad teórica en comunicación (en Carrasco y Saperas, 2013a, pp. 966). En el mismo número, aparecen artículos reveladores por su título como el de Annie Lang, Discipline in Crisis? The Shifting Paradigm of Mass Communication Research. En tal sentido, 
la prospectiva contemporánea sugerida por Carrasco y Saperas (2013a) es la de que los actuales modelos hegemónicos dominantes en lo económico, lo político, lo tecnológico y lo cultural estarían encontrando su correlato en la academia y en la investigación comunicativa.

Para Martino (2001), la prospectiva muestra que el problema de la fundamentación teórica en comunicación sigue vigente:

El problema de las teorías de la comunicación no puede ser tratado pasando de largo sobre la cuestión fundamental de la definición del saber comunicacional. No basta con que discutamos lo que es teoría 0 el motivarnos a su producción, es necesario que sepamos lo que es comunicación, lo que hace de ella una teoría de la comunicación (pp. 135-137).

En suma, si el acumulado histórico hasta la primera década de 2000 es el de una dispersión teórica de la/s teoría/s de la comunicación, se requiere ahora de una nueva visión prospectiva que tenga en cuenta los dos factores constitutivos: el tránsito recíproco entre el problema epistemológico y lo que sucede en la producción teórica sobre la comunicación.

Por otro lado, y en el contexto contemporáneo, al cual se refieren Dogan y Pahre (1993) en su obra Las nuevas ciencias sociales. La marginalidad creadora, de un movimiento de recomposición, innovación y rearticulación transdisciplinar en sectores híbridos entre las ciencias sociales y naturales, y en la línea de Wallerstein (2005), aunque sin referirse directamente a estos autores, la investigadora brasilera Vasallo Lopes (2001) centra su visión prospectiva en la afirmación de un campo transdisciplinario, con un estatuto transdisciplinario de la comunicación.

Cabe reconocer, entonces, que, si bien la formación en paradigmas, teorías y modelos propios de la formación teórica en comunicación sigue teniendo mínima vigencia en las universidades que forman profesionales en comunicación, tal formación teórica se ha transformado en lugar de producción discursiva refinada, instrumental sobre las transformaciones socioculturales, tecnológicas y comunicacionales actuales, en el cual se forman profesionales de la comunicación, a modo de "intelectuales orgánicos" 
para las corporaciones nacionales o transnacionales. Se delata así una falta de perspectiva y enfoque analítico-crítico desde la comunicación sobre asimetrías y contradicciones sociales, políticas, económicas, culturales, comunicacionales en los actuales procesos de globalización capitalista de mercados (Mattos, 2005).

Así, desde hace varias décadas, la prospectiva sobre el campo de la comunicación es la de "producción social de sentido sobre la producción social de sentido", donde el espacio de producción teórica en comunicación, y el que reflexiona sobre la naturaleza misma de este campo, son complementarios (Fuentes, 1998, citado en Vidales, 2010a, p. 62).

A su vez, resulta muy pertinente la propuesta de Arias y Roncallo (2012) de subrayar la necesidad de un nuevo modo de plantear la pregunta acerca de la unidad y definición del campo. Muchos siguen considerando el planteamiento de la definición del campo en versión "moderna", es decir, de una dualidad excluyente, que escoge como respuesta una sola opción entre lo unitario y lo fragmentado. Otros prefieren adoptar una respuesta desde una visión "posmoderna", es decir, la de aceptar que dentro de la comprensión de una multiplicidad de "fragmentos" se da la construcción de unidades de sentido en condiciones performativas particulares del conocimiento. Así la visión histórica del campo, más que representarla en una visión de linealidad directa y secuencial de autores o movimientos, o de supuestos "paradigmas revolucionarios" de radical ruptura de un movimiento a otro, habría que percibirla más bien como una superposición de narrativas paralelas, interrumpidas y reiniciadas, que crean una compleja cartografía, sin pretensión alguna de encontrar un gran principio de unidad y cohesión.

En ese sentido, estos últimos autores, siguiendo la propuesta de Downing (2003, citado en Arias y Roncallo, 2012, p. 219) ${ }^{11}$ de transformar el modo como se plantea la pregunta, sugieren un nuevo modo de pregun-

11 Indicando la propuesta de Downing de cambiar los objetos de estudio dentro de un campo consolidado. También allí estos autores explican ampliamente el alcance y la connotación que quieren darle al concepto 'política' como explicación del desplazamiento de una pregunta epistemológica a una dimensión política de esta en el campo de los estudios en comunicación. 
tar sobre el campo. En vez de preguntar: “¿Existe una unidad en el campo de la investigación en comunicación?”, tal vez es más necesario preguntar: "¿Qué tipo de narrativa e idea de unidad estamos produciendo hoy — qué estamos privilegiando y qué estamos dejando afuera-?", lo cual implicaría ir más allá de la preocupación epistemológica y centrarse más en una aproximación política a las consecuencias de cierto modo de preguntar.

La propuesta de estos autores para el campo, en el fondo, es la de

[...] deconstruir sus propios términos al mismo tiempo que expande sus objetos. La reflexión epistemológica acerca de los límites del campo debe ser al mismo tiempo una reflexión política de los términos en los que el campo se piensa a sí mismo (Arias y Roncallo, 2012, p. 223).

Lo anterior equivale a preguntarse sobre un modo particular de construcción de la realidad y sobre cómo el campo de la comunicación se inserta en ella. Es decir, ser capaz de pensar el "entre" de las oposiciones, atreviéndose a pensar en las oposiciones entre lo unitario y lo fragmentado.

Sin pretender cerrar el debate, cabe decidir reflexivamente, para el desarrollo actual de la investigación en comunicación y para el futuro del campo, si permanecer dentro de la uniformidad lineal con visión de nuevos integrados, o si dar el salto hacia la complejidad dialéctica de lo real, de una ecología mediática que requiere nuevos indicadores de pensamiento, más palpables en el siglo XXI, y volvernos a preguntar con Downing: "Dónde debemos ir ahora y por qué probablemente no lo haremos".

\section{Referencias}

Águila Coghlan, J. C. y Cortés Vásquez, J. (2011). Encuentros y desencuentros: paradigmas, modelos y objetos de estudio de la docencia e investigación en comunicación. Recuperado el 7 de enero de 2015 de http://www.aeic.org/tarragona2012/contents/download/InvestigarlaComunicacionenEspana_Abril2011.pdf 
Alsina, M. R. (1989). Los modelos de la comunicación. Madrid: Tecnos.

Alsina, M. R. (2001). Teorías de la comunicación: ámbitos, métodos y perspectivas (vol. 11). Barcelona: Universidad Autónoma de Barcelona.

Anderson, J. A. (1996). Communication theory: Epistemological foundations. Nueva York: Guilford Press.

Arias Herrera, J. C. y Roncallo Dow, S. (2012). Reordenando la reflexión. De la epistemología a la política. Algunas preguntas sobre el campo de la comunicación. Logos, 21, 213-228.

Armand y Michéle Mattelart (1997). Historia de las teorías de la comunicación. Buenos Aires: Paidós.

Beck, U., Lash, S. y Giddens, A. (1997). Modernización reflexiva: política, tradición y estética en el orden social moderno. Madrid: Alianza Editorial.

Berelson, B. (2004). The state of communication research. En J. Peters, y P. Simonson (eds.), Mass communication and social thought. Maryland: Rowman \& Li\&le!eld.

Berger, C. R., Martino, L. C. y Craig, R. T. (2007). Teorias da comunicação: muitas ou poucas? Ateliê Editorial.

Boyd-Barrett, O. (2006). Publishing research and communications curriculum under globalization. En K. W. Leung, J. F. Kenny y P. S. Lee (eds.), Global trends in communication education and research (pp. 235-259). Cresskill, NJ: Hampton Press.

Braga, J. L. (2007). Introdução: pequeno roteiro de um campo não traçado. En J. Ferreira, Cenários, teorias e epistemologias da Comunicação (pp. 7-21). Río de Janeiro: E-papers.

Brier, S. (2008). Cybersemiotics: Why information is not enough! Toronto: University of Toronto Press. 
Carey, J. W. (1989). Part I. Communication as culture. En Communication as culture. Essays on media and society (pp. 13-110). Nueva York y Londres: Routledge.

Carrasco Campos, A. y Saperas Lapiedra, E. (2013a). Las teorías de la comunicación hoy: contexto histórico, cambios tecnológicos y nuevo estatuto epistemológico de la investigación comunicativa. En Investigar la comunicación hoy. Revisión de políticas científicas y aportaciones metodológicas: Simposio Internacional sobre Politica Científica en Comunicación (pp. 959-970). Segovia: Universidad de Valladolid, Facultad de Ciencias Sociales, Jurídicas y de la Comunicación. Recuperado el 7 de enero de 2015 de http:/ / dialnet.unirioja.es/servlet/articulo? codigo $=4230485$

Carrasco Campos, A. y Saperas Lapiedra, E. (2013b). Tendencias internacionales de la investigación en comunicación actual: modalidades de investigación, objetos de estudio y usos de la teoría en los papers de Journal of Communication (2008-2013). En Espacios de comunicación: IV Congreso Internacional de la Asociación Española de Investigación en Comunicación (p. 1712). Asociación Española de Investigación de la Comunicación.

Craig, R. T. (1999). Communication theory as a field. Communication Theory, 9(2), 119-161.

Craig, R. T. (2008). Communication as a field and discipline. En W. Donsbach (ed.), The international encyclopedia of communication (pp. 675-688). Londres: Blackwell Publishing.

Dogan, M. y Pahre, R. (1993). Las nuevas ciencias sociales: la marginalidad creadora. México: Grijalbo.

Donsbach, W. (2006). The identity of communication research. Journal of Communication, 56(3), 437-448. 
Escarpit, R. (1977). Teoría general de la información y la comunicación. Icaria: Barcelona.

Ferreira, J. (2007). Cenários, teorias e epistemologias da comunicação. Río de Janeiro: E-papers.

Ferreira, G. M., Hohlfeldt, A., Martino, L. C. y de Morais, O. J. (2010). Teorias da comunicação: trajetórias investigativas. Porto Alegre: EDIPUCRS.

Fuentes Navarro, R. (1999). La investigación de la comunicación en América Latina: condiciones y perspectivas para el siglo XXI. Comunicación y Sociedad, 36, 105-132.

Galindo, J. (coordinador) (2008). Comunicación, ciencia e historia. Fuentes científicas históricas hacia una comunicología posible. Madrid: Mc-Graw Hill.

Giddens, A. (1995). La constitución de la sociedad: bases para la teoría de la estructuración. Buenos Aires: Amorrortu.

Hanitzsch, T. (2013). Writing for communication theory. Communication Theory, 23(1). Recuperado el 12 de marzo de 2015 de http: / / onlinelibrary.wiley.com/doi/10.1111/comt.2013.23.issue-1/issuetoc

Holmes, D. (2013). Communication theory. En M. Donesi (ed.), Encyclopedia of media and communication (pp. 185-188). Toronto: University of Toronto Press.

Jensen, K. B. (1995). The social semiotics of mass communication. Londres: Sage Publications, Incorporated.

Jensen, K. B. (2002). The humanities in media and communication research. En A handbook of media and communication research. Qualitative and quantitative methodologies (pp. 15-39). Londres y Nueva York: Routledge. 
Jensen, K. B. (2010). Communication theory and philosophy. En W. Donsbach (ed.), The international encyclopedia of communication (vol. III, pp. 839-852). Blackswell Publishing.

Krippendorff, K. (1994). The past of communication's hoped-for future. En M. R. Levy y M. Gurevitch (eds.), Defining media studies: Reflections on the future of the field (pp. 42-52). Oxford: Oxford University Press.

Lozano, A. C. y Mariño, M. V. (2010). La enseñanza universitaria de las teorías de la comunicación en Europa y América Latina. Revista Latina de Comunicación Social, 65, 20.

Lyotard, F. (1987). La condición posmoderna. Madrid: Cátedra.

Martín-Barbero, J. (2000). Globalización y multiculturalidad: notas para una agenda de investigación. En M. Moraña (ed.), Nuevas perspectivas desde/sobre América Latina: el desafío de los estudios culturales (pp. 17-27). Barcelona: Cuarto Propio.

Martín Serrano, M. (1990). La epistemología de la comunicación, a los cuarenta años de su nacimiento. Telos, 22, 65-76.

Martín Serrano, M. (2006). ¿Para qué sirve estudiar teoría de la comunicación? Contratexto: Revista digital de la Facultad de Comunicación, 4. Recuperado el 12 de marzo de 2015 de http://www.ulima.edu. pe/revistas/contratexto/pdf/art2.pdf

Martín Serrano, M. (2007). Teoría de la comunicación. La comunicación, la vida y la sociedad. Madrid: McGraw-Hill Interamericana.

Martino, L. C. (2001). De qual comunicação estamos falando. En Teorias da comunicação: conceitos, escolas e tendências (pp. 11-26). Petrópolis: Vozes. 
Mattos, M. A. (2005). Desafios da Formação Teórica em Comunicação Social no Cenário Contemporâneo. Contemporánea, 5. Recuperado el 23 de marzo de 2015 de http://www.contemporanea.uerj.br/ pdf/ed_05/contemporanea_n05_05_mariaangela.pdf

Merton, R. K. (1949). Teoría y estructura sociales. México: Fondo de Cultura Económica.

Orozco, L. A. y Chavarro, A. (2010). Robert K. Merton: la ciencia como institución. Revista de Estudios Sociales, 37, 143-162.

Piñuel Raigada, J. L. (2010). La comunicación como objeto científico de estudio, como campo de análisis y como disciplina científica. Contratexto: revista de la Facultad de Comunicación de la Universidad de Lima, 18, 67-107.

Peters, J. D. (2012). Speaking into the air: A history of the idea of communication. Chicago: University of Chicago Press.

Rizo García, M. (2006). Manuales de teorías de la comunicación: análisis desde la comunicología. Barcelona: Universidad Autónoma de Barcelona.

Rizo García, M. (2010). Formación teórica en comunicación: la historia del pensamiento comunicacional en el plan de estudios de la Licenciatura en Comunicación y Cultura de la Universidad Autónoma de la Ciudad de México. Diálogos de la Comunicación, 80, 3. Recuperado el 23 de marzo de 2015 de http: / / dialnet.unirioja.es/servlet/ articulo? codigo=3719691 (Fecha de consulta: marzo 23 de 2015).

Rizo García, M. (2012). Imaginarios sobre la comunicación. Algunas certezas y muchas incertidumbres en torno a los estudios de comunicación, hoy. Barcelona: Bellaterra-Institut de la Comunicació, Universitat Autònoma de Barcelona.

Roncallo D., S. (2013). Entre la interdisciplinariedad, las disciplinas y los objetos. Palabra Clave, 16(2), 276-281. 
Roncallo D., S. (2014). ¿Integrados? (Una muy breve reflexión). Palabra Clave, 17(1), 7-12.

Sá Martino, L. M. (2008). A ilusão teórica no campo da comunicação. Revista FAMECOS: Mídia, Cultura e Tecnologia, 1(36), 111-117.

Sá Martino, L. M. (2014). O diálogo Norte-Sul em teoria da comunicação: hegemonias, apropriações e resistências nas pesquisas anglo-saxônicas e latino-americanas. Comunicação \& Sociedade, 36(1), 107-132.

Saperas, E. (2013). Comunicación mediática y sociedad: manual de teorías de la comunicación. Madrid: OMM Editorial.

Scolari, C. (2008). Hipermediaciones. Elementos para una teoría de la comunicación digital interactiva. Barcelona: Gedisa.

Shannon, C. E. y Weaver, W. (1949). The mathematical theory of communication. Illinois: Univ of Illinois Press.

Shepherd, G.J.,John, J. St. y Striphas, T. (eds.) (2006). Introduction: Taking a stand on theory. En Communication as... Perspectives on theory (pp. XI-XIX). Thousand Oaks, California: Sage.

Sierra, F. (2002). Transformaciones epistemológicas. En Simposio Permanente sobre Universidad. Bogotá: Pontificia Universidad Javeriana.

Sierra, L. I. (2005). Una aproximación trans e interdisciplinaria del campo de la comunicación. Conexão-Comunicação e Cultura, 4(8), 81-100.

Sodré, M. (2012). Comunicação: um campo em apuros teóricos. MATRIZes, 5(2), 11-28.

Torrico, E. (2004). Abordajes y periodos de la teoría de la comunicación. Buenos Aires: Norma.

Vattimo, G. (2000). El fin de la modernidad: nihilismo y hermenéutica en la cultura posmoderna. Barcelona: Gedisa. 
Vasallo de Lopes, M. I. (1999). Reflexiones sobre el estatuto disciplinario del campo de la comunicación. En M. Vasallo de Lopes y R. Fuentes Navarro (comps.), Comunicación, campo y objeto de estudio. Perspectivas reflexivas latinoamericanas (pp. 43-58). Guadalajara: ITESO, UAA, Ucol, UdeG.

Vasallo de Lopes, M. I. (2001). Reflexiones sobre el estatuto disciplinario del campo de la comunicación. En M. Vasallo de Lopes y R. Fuentes Navarro (comps.), Comunicación, campo y objeto de estudio. Perspectivas reflexivas latinoamericanas (p. 44). Guadalajara: ITESO, UAA, Ucol, UdeG.

Vasallo de Lopes, M. I. (2014). Mediação e recepção. Algumas conexões teóricas e metodológicas nos estudos latino-americanos de comunicação. MATRIZes, 8(1), 65-80.

Veiga França, V. (2014). Crítica e metacrítica: contribuição e responsabilidade das teorias da comunicação. MATRIZes, 8(2), 101-116.

Vidales, C. (2010a). Semiótica y teoría de la comunicación (t. I, pp. 7-10). México: CAIEP.

Vidales, C. (2010b). Semiótica y teoría de la comunicación: una propuesta de un punto de vista comunicológico. Razón y Palabra, 72, 3-25. Recuperado el 23 de marzo de 2015 de http://www.razonypalabra.org.mx/

Vidales, C. (2011). El relativismo teórico en comunicación. Entre la comunicación como principio explicativo y la comunicación como disciplina práctica. Comunicación y Sociedad, 16, 11-45. Recuperado el 15 de abril de 2015 de http://www.scielo.org.mx/scielo. php?script=sci_arttext\&pid=S0188-252X2011000200002

Wallerstein, I. (2001). Abrir las ciencias sociales. México: Siglo XXI.

Wallerstein, I. (2005). Las incertidumbres del saber. Barcelona: Gedisa. 